\title{
Osgood-Schlatter disease
}

INSERM

\section{Source}

INSERM. (1999). Orphanet: an online rare disease and orphan drug data base. OsgoodSchlatter disease. ORPHA:97335

Osgood-Schlatter disease is a traction apophysitis of the anterior tibial tubercle described in active adolescents and characterized by gradual onset of pain and swelling of the anterior knee causing limping that usually disappears at the end of growth. 